IMECE2015-51581

\title{
NUMERICAL ANALYSIS OF DESIGN PARAMETERS WITH STRONG INFLUENCE ON THE AERODYNAMIC EFFICIENCY OF A SMALL-SCALE SELF-PITCH VAWT
}

\author{
Carlos Xisto* \\ Chalmers University of Technology \\ Dep. of Applied Mechanics \\ Division of Fluid Dynamics \\ SE-41 296, Gothenburg, Sweden \\ Email: carlos.xisto@chalmers.se
}

\author{
José Páscoa \\ Dep. de Eng. Electromecânica \\ Universidade da Beira Interior \\ 6200-Covilhã,Portugal \\ Email: pascoa@ubi.pt
}

\author{
Michele Trancossi \\ Dep. of Sc. and Methods for Engineering \\ UNIMORE \\ Reggio-Emilia, 42122, Italy \\ Email: michele.trancossi@unimore.it
}

\begin{abstract}
In the paper, four key design parameters with a strong influence on the performance of a small-scale high solidity variable pitch VAWT (Vertical Axis Wind Turbine), operating at low tip-speed-ratio (TSR) are addressed. To this aim a numerical approach, based on a finite-volume discretization of twodimensional Unsteady RANS equations on a multiple sliding mesh, is proposed and validated against experimental data. The self-pitch VAWT design is based on a straight blade Darrieus wind turbine with blades that are allowed to pitch around a feathering axis, which is also parallel to the axis of rotation. The pitch angle amplitude and periodic variation are dynamically controlled by a four-bar-linkage system. We only consider the efficiency at low and intermediate TSR, therefore the pitch amplitude is chosen to be a sinusoidal function with a considerable amplitude. The results of this parametric analysis will contribute to define the guidelines for building a full size prototype of a small scale turbine of increased efficiency.
\end{abstract}

\section{NOMENCLATURE}

A Rotor disk area $\left(\mathrm{m}^{2}\right)$

$c \quad$ Blade chord length $(\mathrm{m})$

$C_{P} \quad$ Coefficient of power

$I$ Turbulence intensity (\%)

$l$ Turbulence length scale $(\mathrm{m})$

$M$ Torque (N.m)
$N \quad$ Number of rotor blades

$P \quad$ Power (W)

$S \quad$ Blade span (m)

$t$ Time (s)

$T$ Thrust (N)

$U_{\text {wind }}$ Wind velocity $\left(\mathrm{m} . \mathrm{s}^{-1}\right)$

$U_{t} \quad$ Blade tip velocity $\left(\mathrm{m} . \mathrm{s}^{-1}\right)$

$x^{\prime}$ coordinate of the reference frame $\left(x^{\prime}, y^{\prime}\right)$, due to the oscillating and rotating motion of the blades, with origin in the blade leading edge

$\alpha \quad$ Blade angle of attack $\left(^{\circ}\right)$

$\varepsilon \quad$ Phase angle of eccentricity $\left(^{\circ}\right)$

$\lambda$ Tip-speed ratio

$\omega$ Angular pitching velocity ( $\mathrm{rad} / \mathrm{s})$

$\theta \quad$ Pitch angle $\left({ }^{\circ}\right)$

$\sigma$ Rotor solidity

$\Psi \quad$ Azimuthal blade position $\left(^{\circ}\right)$

$\Omega$ Rotational Velocity (RPM)

$\rho$ Air density $\left(\mathrm{kg} \cdot \mathrm{m}^{-3}\right)$

\section{INTRODUCTION}

Vertical Axis Wind Turbines (VAWTs) can be classified as being drag-based or lift-based devices. Lift-based, or Darrieus, wind turbines are composed by a set of straight, or curved troposkein-shaped airfoils, that generate power by converting the tangential component of lift into positive torque. The curved troposkein-shaped blade design was proposed in order to reduce 


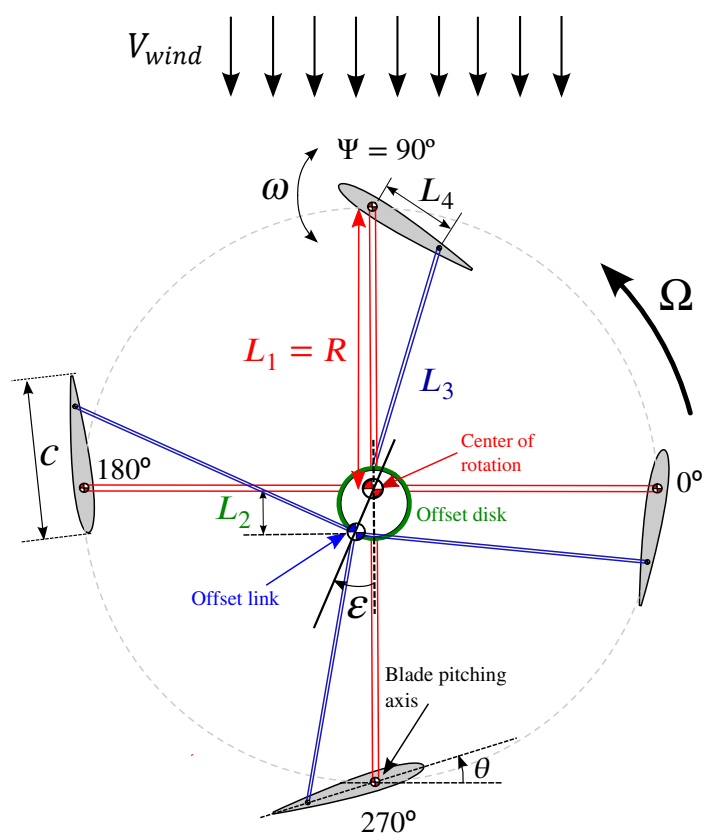

(a)

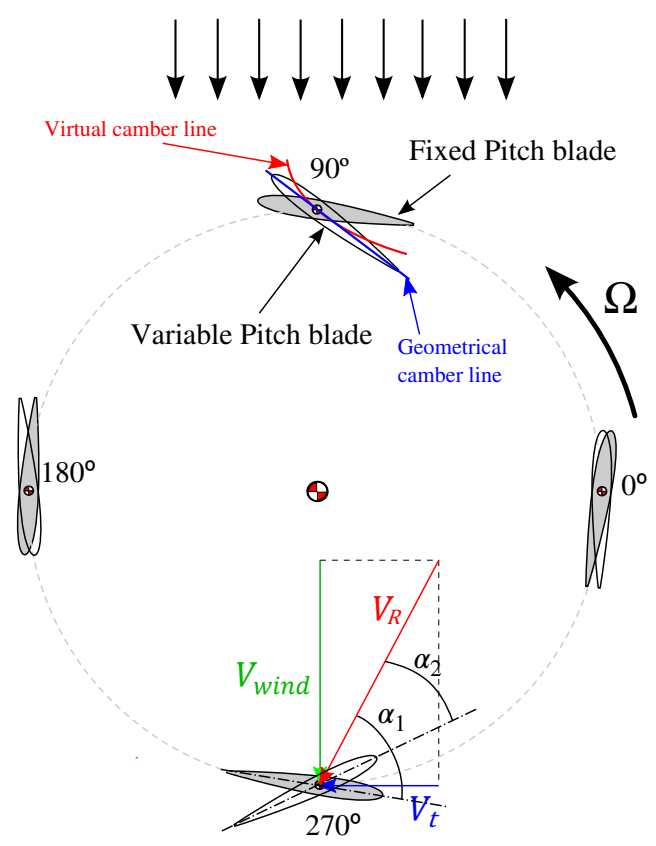

(b)

FIGURE 1. a) VARIABLE PITCH VAWT WITH A FOUR-BAR-LINKAGE PITCHING SYSTEM; b) COMPARISON BETWEEN THE VELOCITY VECTORS AT LOW TIP-SPEED-RATIO BETWEEN A VARIABLE AND FIXED PITCH VAWT. $V_{t}=\Omega R$ IS THE TIP SPEED VELOCITY AND $V_{R}=\sqrt{V_{\text {wind }}^{2}+V_{t}^{2}}$ IS THE RESULTANT VELOCITY ON THE BLADE. ONE CAN OBSERVE THAT, IN THE BACKWARD REGION OF THE VAWT $\left(\Psi=270^{\circ}\right)$, THE ANGLE OF ATTACK, $\alpha$, IS HIGHER FOR THE FIXED PITCH VAWT $\left(\alpha_{1}>\alpha_{2}\right)$.

the structural centrifugal loads. The straight-blade rotor, also known as H-rotor, is more sensible to the centrifugal loads, but have a more useful area of operation since the entire span of blade length is operating at the same tip speed. Nevertheless, these turbines are limited to the amount of energy that they can extract from the wind, which is normally lower than the one gathered by horizontal axis wind turbines (HAWT). In order to not loose wind energy resources, a new technology of VAWT that can have a superior or equivalent efficiency than HAWT is required. We propose a concept of a dynamic self-pitch VAWT. There are several aspects in which a variable pitch design can improve when compared with classical VAWTs and HAWTs, see reference [1] for more details.

In this paper a small scale, self-pitch, high solidity VAWT is proposed for urban applications of micro electricity generation. The turbine is designed to operate at low and intermediate tip-speed-ratios $(0.5<\lambda<1.5)$ for noise reduction. The rotating blades are allowed to pitch around a feathering axis that is parallel to the axis of rotation. The pitch schedule and amplitude is controlled by a four-bar-linkage type mechanism, see Fig 1 (a) [2], which is very similar to the Voith-Schneider wind turbine [3]. While using this system it is possible to improve the azimuthal load distribution and energy conversion at low and intermediate $\lambda$. A pure straight blade Darrieus turbine is normally composed by classic symmetric blade section profiles, these being usually designed to operate at small angles of attack $(\alpha)$. If a critical $\alpha$ is achieved, the flow separates from the low pressure surface of the airfoil and the blade experiences stall. In a conventional fixed pitch VAWT each blade experiences a periodic variation of $\alpha$, which has contributions from the incoming wind and rotational speeds, see Fig. 1 (b). At high values of $\lambda$ the amplitude of $\alpha$ variation decreases and, as $V_{t}>>V_{\text {wind }}$, the variation is almost negligible. Conversely, at intermediate $\lambda$, due to a large cyclic variation of $\alpha$, the blades on the rear half (with respect to wind direction, $\Psi=270^{\circ}$ ) experience stall. At low $\lambda$ this effect is even more severe, consequently the turbine produces none or very low torque and loses the ability to self-start. With the proposed concept a pitching schedule for the blades is defined as a function of their position in the rotating cycle. The oscillating movement of the blades minimize the variation of the angle of attack, thus reducing stall effects in the rear half of the rotor for low and intermediate $\lambda$ values. For low $\lambda$ the blades could even be orientated to act as more efficient drag devices allowing to produce enough torque to start the turbine [4].

The efficiency of a wind turbine can be estimated through the power coefficient, $C_{P}$, which describes how much energy is possible to extract from the wind. HAWTs normally reach values of $C_{P}=0.4$ to $C_{P}=0.45$ [5]. In VAWTs $C_{P}$ values of 0.4 
to 0.43 were obtained 20 years ago [6] when many researchers proved, experimentally and analytically, that VAWTs can reach comparable performance levels to their horizontal axis counterparts. There are several aspects that could affect the performance of a wind turbine, namely the design of an optimized airfoil [7]; the modification of rotor solidity $[5,8]$; or the inclusion of a variable pitch mechanism [9]. In the present paper several of these geometrical parameters are analyzed in a variable pitch VAWT.

In the next section the pitch mechanism and the equations that express the oscillating motion of the blades are briefly presented. Afterwards the two-dimensional numerical method is presented and validated with the available experimental data. The influence of the geometrical parameters are then analyzed and finally the optimized design is compared with a fixed pitch VAWT.

\section{Variable pitch VAWT for improved aerodynamic effi- ciency}

The recent developments on cyclogyros for aeronautics will be incorporated in the present work to solve the problems of variable pitch vertical turbines. Through this cross-fertilization we propose, as a first approach, the pitching mechanism as shown in Fig. 1 (a) [2]. It consists of three fixed lengths, $L_{1}, L_{3}$ and $L_{4}$ and it is controlled by the length and orientation of $L_{2}$. In the proposed design the $L_{1}$ bar is equal to the rotor radius and is connected to the blade in the respective pitching axis. The $L_{3}$ bar is connected near the blade trailing edge, and the distance between these two connections is $L_{4}$. All the links between the bars are free to rotate. Such mechanism allows for a cyclic pitching of the blades as they follow the path of rotation.

The dynamic pitching provided by the four-bar-linkage mechanism is expressed by the following equation:

$$
\theta=\frac{\pi}{2}-\sin ^{-1}\left[\frac{L_{2}}{a} \cos (\Psi+\varepsilon)\right]-\cos ^{-1}\left[\frac{a^{2}+L_{4}^{2}-L_{3}^{2}}{2 a L_{4}}\right]
$$

where,

$$
a^{2}=L_{2}^{2}+R^{2}-2 L_{2} R \cos \left(\Psi+\varepsilon+\frac{\pi}{2}\right)
$$

The pitch angular speed is given by the time derivative of $\theta$,

$$
\omega=\frac{d \theta}{\mathrm{d} t}=\frac{d \theta}{d \Psi} \cdot \frac{d \Psi}{d t}=\frac{d \theta}{d \Psi} \cdot \Omega
$$

This mechanism, which has proved well for cyclogyros used in aeronautical propulsion [10,10-12,12-15], is simple, reliable and has the ability to self-adjust the turbine dynamics as a func- tion of the rotating speed of the rotor, and also on the direction and magnitude of the incoming wind. It is noted that the system kinematics also allows for an asymmetric pitching schedule of the blades, which could be beneficial since the frontal area of the rotor operates at a different angle of attack than the rear region. However, an increase in power penalty due to the friction losses, as well the increasing possibility of system failure are anticipated consequences of adding more moving parts into the VAWT. Further, the pitching system needs to be self-aware of the wind conditions (direction and intensity) and rotational speed of the rotor. A set of sensors is therefore required and an intelligent control system needs to be devised, in order to assert the optimal rotor operational conditions that meet both aerodynamic efficiency and system structural integrity.

\section{NUMERICAL METHOD AND VALIDATION}

The numerical methodology employed in this work is based on a finite-volume implementation of the incompressible, Unsteady Reynolds-Averaged Navier-Stokes (URANS) equations on two-dimensional hybrid grids. For simulating the rotational motion of the rotor, as well as the oscillating motion of the blades, a sliding-mesh method is used. The assumption of incompressible flow is justified on the basis of the maximum velocities involved. A pressure-based coupled algorithm is used for solving the equations, which allows performing unsteady computations with a Courant number of order 100 within each timestep. The remaining specifications of the numerical method, which will be use throughout the entire paper are described in Table 1.

We start by validating the numerical model with the available experimental data. To this end, data for a cyclogyro of similar dimensions as the wind turbine, operating in propulsion mode $\left(V_{\text {wind }}=0\right)$, is used. This configuration, here denominated IAT21-L3 rotor, was analysed as a part of a major European ongoing project, which aims to develop the cyclogyro technology as a mean of propulsion for small and medium size aircraft $[12,15-19]$. It is obvious that the results obtained for the IAT21-L3 rotor does not faithfully represent the features of a VAWT, since in propulsion mode energy is being provided and not extracted from the flow. Nevertheless, the IAT21-L3 rotor comprises similar aerodynamic features that will allow us to validate the CFD model in terms of relative unsteady blade flows. Moreover, other authors have employed similar numerical models for studying the flow on classical VAWT $[20,21]$, which indicates that the current numerical framework can be considered satisfactory for analysing the flow in the proposed design. If a more detailed description of the flow is to be achieved, e.g. simulation of dynamic stall [22-24], the usage of detached eddy simulation or large eddy simulation models is required.

The IAT21-L3 rotor is composed by six NACA0016 blades with a chord and span equal to $c=0.3 \mathrm{~m}$ and $S=1 \mathrm{~m}$, respec- 
TABLE 1. NUMERICAL FRAMEWORK USED IN THE ENTIRE PAPER.

\begin{tabular}{ll}
\hline Solver & Pressure-based coupled solver; 2D; double-precision; sliding-mesh; URANS \\
\hline Boundary Conditions & Viscous wall (no-slip); Uniform flow velocity inlet/outlet; $I=5 \% ; l=0.02 c$ \\
Fluid type & Incompressible air \\
Spatial discretization & Second-order linear upwind; central-differences \\
Time discretization & Second-order implicit \\
Turbulence modeling $\left(y^{+}<1\right)$ & k- $\omega$ SST/ Spalart-Allmaras \\
Grid size (IAT21) & 300,000 cells (grid-0); 600,000 cells (grid-1) \\
\hline
\end{tabular}

tively, the rotor radius is equal to $R=0.5 \mathrm{~m}$. The pitching axis is located at $35 \%$ of the chord length and the distance between the pitching axis and the control rod is $L_{4}=0.120 \mathrm{~m}$. The periodic pitching schedule varies from $\theta=+36^{\circ}$, in the top section of the rotor $\left(\Psi=90^{\circ}\right)$, to $\theta=-39^{\circ}$ in the bottom section of the rotor $\left(\Psi=270^{\circ}\right)$, resulting in an asymmetric pitching profile. This blade pitch angle variation is described by Eqn. (1) and the angular velocity, $\omega$, of the oscillating blades is given by Eqn. (3). The length of the control $\operatorname{rod}\left(L_{3}=0.61 \mathrm{~m}\right)$, the magnitude of eccentricity $\left(L_{2}=0.073 \mathrm{~m}\right)$ and the phase angle of eccentricity $\left(\varepsilon=0^{\circ}\right)$ were defined in order to obtain the desired pitching profile.

Figure 2 shows the numerical domain and boundary conditions, together with a close-up of the rotor and blade $\left(\Psi=120^{\circ}\right)$ computational grids. The overall domain comprises three circular zones, which are separated by sliding-mesh interfaces. The first zone is the so called "Environment" that is fully covered by a stationary ( $\Omega=0)$ unstructured grid; the second zone is the "Rotor" that is also covered by an unstructured grid, but is rotating in the counter-clockwise direction with a rotating speed $\Omega$; and finally the third zone is the "Blade" domain, which is composed by an hybrid grid comprising a fully structured O-type mesh in the boundary layer region, in order to comply with $y^{+}<1$, and a fully unstructured grid in the remaining domain. Each blade domain is centered in the pitching axis and prescribes an oscillating motion, $\omega$, given by Eqn. (3). The boundary conditions are specified in the following way: for the validation test case the outer circle BC works as an outlet, where the atmospheric pressure is specified; for the VAWT test cases a velocity $U_{\text {wind }}$ is imposed together with a turbulence intensity, $I$, of $5 \%$, which is a typical value for wind and a turbulence length scale of $l=0.02 c$. It is noted that in the Spalart-Allmaras (SA) turbulence model there is no significant term that provides a decay in turbulence intensity from the freestream boundary until the rotor [25], therefore for such a model a value o $I=5 \%$ on the rotor is also expected.

Results are obtained for several rotating speeds, $100<\Omega<$
1000 , which means that the chord based Reynolds number is in the range of $12,560<\operatorname{Re}_{c}<1,256,600$. For each value of $\Omega$ a total of twenty rotations are computed, but a time-converged periodic solution is obtain after ten revolutions. Therefore, thrust and power are presented in terms of time-average data obtain for the last ten rotations of each $\Omega$. For the VAWT test case a periodic solution is obtained after the first two rotations, in that case only the last three revolutions of a total of five were used for obtaining the time-average values of $C_{P}$. The time-step is defined so as to obtain a rotor azimuthal displacement of $1 / 2^{\circ}$ per time-step [21].

Figure 3 shows a comparison between the numerical results and the experimental data. It is noted that thrust and power vary with the square and cube of rotation speed, respectively. Therefore, in order to verify if the numerical model validates for the entire range of $\Omega$, a $\log _{10}-\log _{10}$ scale was selected. In Fig. 3 (a) the results obtained for the time-averaged variation of thrust with rotation speed are compared with experiments. The numerical results are also compared with each other in terms of turbulence model (SA, k- $\omega$ SST) and grid refinement (grid-0, grid-1). One can observe that both turbulence models predict the same trend, and that the results do not significantly change as the number of grid points is increased. It is noted that this is a two-dimensional model and that the 3D losses are being neglected, which could explain the discrepancy between the experimental data and CFD results in some plot regions. Figure 3 (b) shows the variation of power with rotational speed. Here the comparison between experiments and CFD shows a better agreement, once again the results do not significantly change with the refinement of the grid. However, in the prediction of power consumption, the SA turbulence model is providing a better answer (less than $10 \%$ of error) than the k- $\omega$ SST model. These are indicators that the results obtained with grid-0 are satisfactory in terms of grid refinement, and that the Spalart-Allmaras model could be used for the remaining part of this paper. 


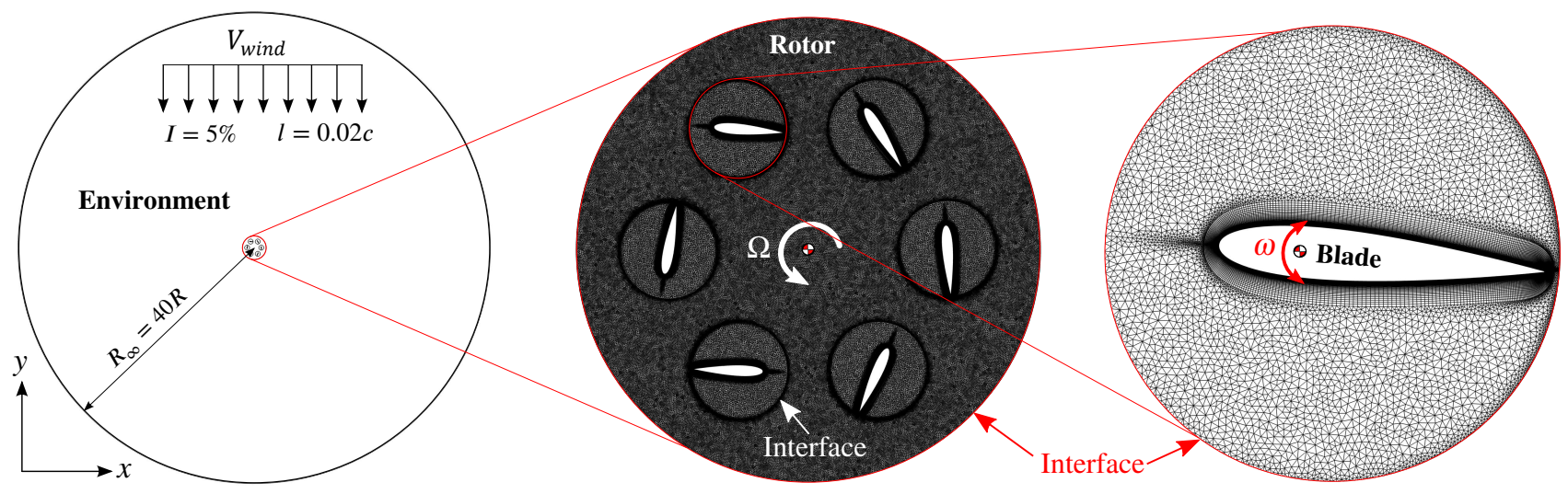

FIGURE 2. TWO-DIMENSIONAL NUMERICAL DOMAIN USED FOR COMPUTING THE IAT21-L3 ROTOR TEST CASE, A CLOSE-UP OF THE ROTOR AND BLADE GRID IS ALSO DISPLAYED. THE GRID IS COMPOSED BY THREE CIRCULAR ZONES, WHICH ARE SEPARATED BY SLIDING-MESH INTERFACES. THE SAME NUMERICAL CONFIGURATION AND BOUNDARY CONDITIONS ARE USED THROUGHOUT THE ENTIRE PAPER.

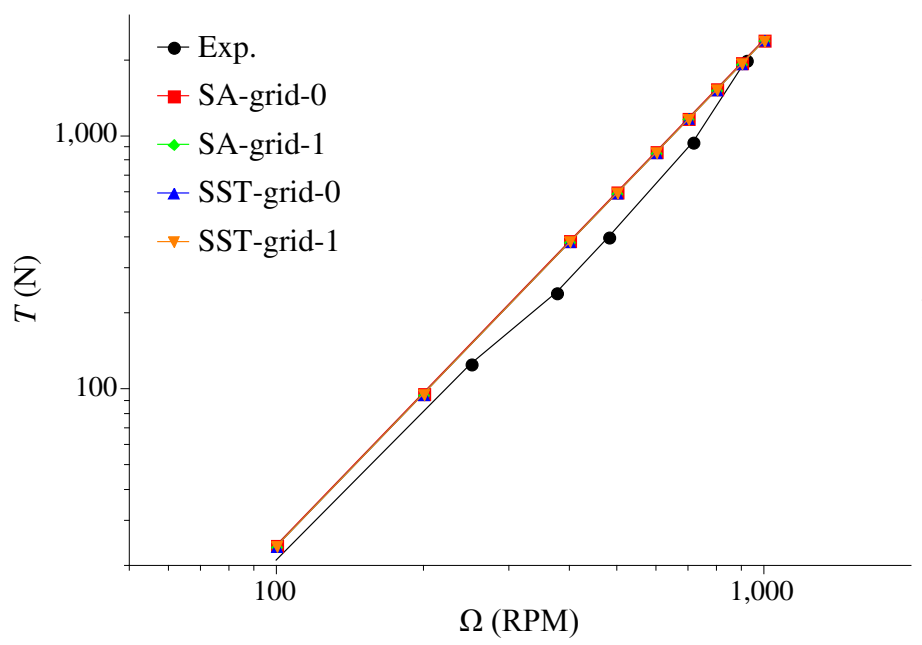

(a)

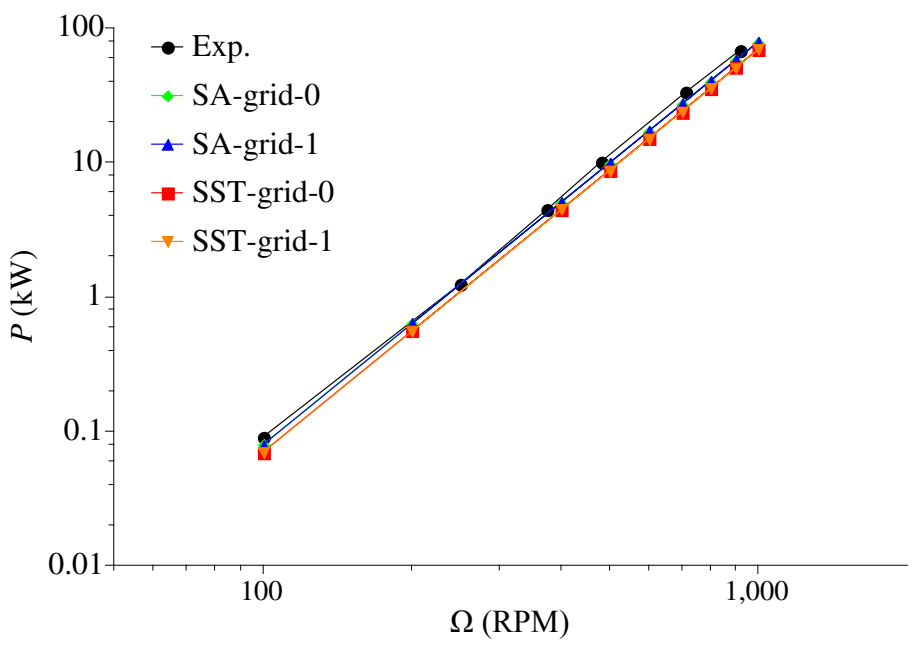

(b)

FIGURE 3. RESULTS OBTAINED FOR THE VALIDATION TEST CASE IN $\log _{10}-\log _{10}$ PLOTS: a) VARIATION OF THRUST WITH ROTATIONAL SPEED; b) VARIATION OF POWER WITH ROTATIONAL SPEED.

\section{ANALYSIS OF TWO-DIMENSIONAL GEOMETRICAL PARAMETERS}

In this section four geometrical parameters influencing the aerodynamic efficiency of a small-scale high solidity VAWT, at low tip-speed-ratios, are analysed. We start by analysing the influence of the airfoil thickness, afterwards the effect of increasing the number of blades is assessed in a $C_{P}$ vs. $\lambda$ plot. The chord-toradius ratio and the pitching axis location are analysed in the following subsections. The rotor dimensions selected for the analysis are listed in Table 2. The rotor diameter and span are equal to $1 \mathrm{~m}$ and the pitch angle amplitude is fixed between $+30^{\circ}$ and $-30^{\circ}$. Such an high value for the amplitude, $\theta$, was chosen since for the lower tip-speed-ratios, $\lambda<1$, an higher pitching angle will give a lower variation of $\alpha$. This is illustrated in Fig. 1 (b), where $\alpha_{2}$ is reduced with an increasing $\theta$. This will no longer be true for the intermediate, $\lambda=1$, and higher, $\lambda>1$, tip-speedratios, since the variation of $\alpha$ decreases with an increasing $\lambda$. Therefore an optimum $\theta$ will exist for a given $\lambda$, and normally $\theta$ should be increased as we decrease $\lambda$. For the parametric analysis a sinusoidal pitch angle equation was used to described the 
oscillatory movement of the blades:

$$
\theta=\theta_{0} \sin \left(\Omega t+\Psi_{0}\right)
$$

The time derivative of Eqn. (4) provides the angular pitching velocity of the blades:

$$
\omega=\dot{\theta}=\theta_{0} \Omega \cos \left(\Omega t+\Psi_{0}\right)
$$

where $\theta_{0}=30^{\circ}$ is the pitch amplitude and $\Psi_{0}$ is the initial blade position. The rotor rotates counter-clockwise and for the entire simulation the rotational speed is fixed, $\Omega=10.47 \mathrm{rad} / \mathrm{s}$ (100 RPM). Therefore, in order to vary the tip-speed-ratio,

$$
\lambda=\frac{V_{\text {wind }}}{V_{t}}
$$

only the wind velocity $V_{\text {wind }}$ varies. In Eqn. (6) $V_{t}=\Omega R$ is blade tip velocity, which is kept constant for the entire range of $\lambda$. In the following subsections the aerodynamic efficiency of the rotor is expressed in terms of power coefficient,

$$
C_{P}=\frac{P}{0.5 \rho A V_{\text {wind }}^{3}}
$$

variation with $\lambda$. The power coefficient relates the power extracted form the wind, $P=M \Omega$, with the total power contained in the wind $P_{\text {wind }}=0.5 \rho \mathrm{A} V_{\text {wind }}^{3}$, where $\rho$ is the density of air, $A=2 R S$ is the rotor disk area and $M$ is the torque.

For the VAWT test case the chord base Reynolds number is both dependent of the rotation speed and wind velocity. It is estimated that $\mathrm{Re}_{c}$ is in the range of $90,000<\mathrm{Re}_{c}<266,000$, which means that it is still in the range of validation.

\section{Airfoil thickness}

We start by analyzing the effect of the airfoil thickness on the aerodynamic efficiency of the rotor. To this end the turbulent flow on four NACA profiles (0006; 0010; 0015; 0018) is computed. In this test case, the number of blades, the chord length and the pitching axis location are fixed parameters, $N=4$; $c=0.25 \mathrm{~m} ; x^{\prime} / c=0.25$, respectively.

Figure 4 (a) shows the variation of $C_{P}$ with $\lambda$ obtained for the different blade profiles. One can observe that, for this specific rotor dimensions, the power extraction with the NACA0006 and NACA0010 blades is significantly lower when compared with the ticker airfoils. However, as the airfoil thickness increases from $15 \%$ to $18 \%$ of the chord length, the increase in power co- efficient is not so pronounced. This behaviour is illustrated in Fig. 4 (b), where $C_{P}$ is plotted as a function of the airfoil thickness, for constant values of $\lambda$. One can observe that the slope of the $C_{P}$ vs. NACA is decreasing with the blade thickness and we can see that a maximum may have been reach for the NACA0018 profile.

\section{Number of blades}

In the second test case the only parameter that varies is the number of blades, $N$. Here the NACA0018 airfoil was select, since it was the one that preformed better in the thickness analysis. The chord length and the pitching axis location are again fixed at $c=0.25 \mathrm{~m}$ and $x^{\prime} / c=0.25$, respectively. It is noted that, by increasing the number of blades, the rotor solidity,

$$
\sigma=\frac{N c}{2 R}
$$

also increases. Another possible effect that results from increasing $N$ is an increase of the aerodynamic interference effects, that could improve or decrease the aerodynamic performance of each blade.

Figure 5 (a) shows the variation of $C_{P}$ with $\lambda$ computed in each one of the four rotors. One can observe that, for the lowest values of $\lambda$ the rotor that preforms better is the one with six NACA0018 blades. In the range of $0.6<\lambda<0.8$ it is the rotor with four blades that is capable of generating more torque. However, after $\lambda=0.8$, the rotor with six blades is again preforming better, since the four bladed rotor is showing a rapid decrease in torque production. The rotors with three and two blades are performing worst for all cases. In Fig. 5 (b) the variation of $C_{P}$ with the number of blades is plotted for constant values of $\lambda$. One can observe that, for low $\lambda$ values, the rotor seems to preform better as more blades are included. However it seems that a maximum is reached with six blades.

\section{Chord-to-radius ratio}

The effect of solidity is now analyzed just by increasing the chord length and keeping the number of blades at a constant value of $N=4$. For the remaining parameters, the values of the previous sections are used $\left(x^{\prime} / c=0.25\right.$; NACA0018). By varying the chord length and keeping the radius constant, one also varies the chord-to-radius ratio. It is known that the $c / R$ ratio can have a strong influence in the turbine aerodynamics due to the flow curvature effects [14]. In curvilinear flow, the local angle of flow incidence and local velocity, along the blade chord line, are functions of radius, $R$, and chord location, $\left(x^{\prime}\right)$. This effect can be represented by a cambered airfoil in linear flow. In the VAWT of Fig. 1 (b), the virtual camber is negative in the rotor top position $\left(\Psi=90^{\circ}\right)$ and positive in the rotor bottom position 
TABLE 2. ROTOR DIMENSIONS AND PARAMETERS THAT WERE ANALYZED FOR THE PROPOSED VAWT DESIGN. FOUR PARAMETERS WERE COMPUTED: THE AIRFOIL THICKNESS; THE NUMBER OF BLADES; THE CHORD-TO-RADIUS RATIO; AND THE LOCATION OF THE PITCHING AXIS, IN TERMS OF PERCENTAGE OF CHORD LENGTH.

\begin{tabular}{|l|l|l|l|}
\hline \multicolumn{2}{|c|}{ Rotor dimensions } & Parameter & Variable \\
\hline Span, $S$ & $1 \mathrm{~m}$ & NACA Profile & $0006 / 0010 / 0015 / 0018$ \\
\cline { 2 - 4 } Radius, $R$ & $0.5 \mathrm{~m}$ & Nr. of blades, $N$ & $2 / 3 / 4 / 6$ \\
\cline { 2 - 4 } Pitch amplitude, $\theta_{0}$ & $30^{\circ}$ & Chord,$c(\mathrm{~m})$ & $0.125 / 0.25 / 0.375$ \\
\cline { 3 - 4 } Rotational speed, $\Omega$ & $100 \mathrm{RPM}$ & PA location $\left(x^{\prime} / c\right)$ & $0.125 / 0.25 / 0.35 / 0.5$ \\
\hline
\end{tabular}

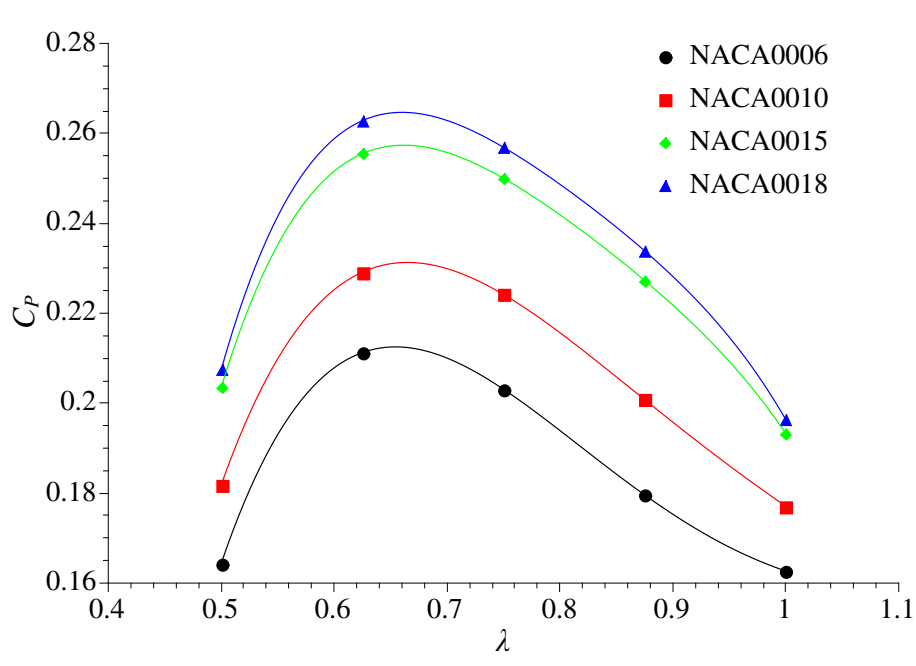

(a)

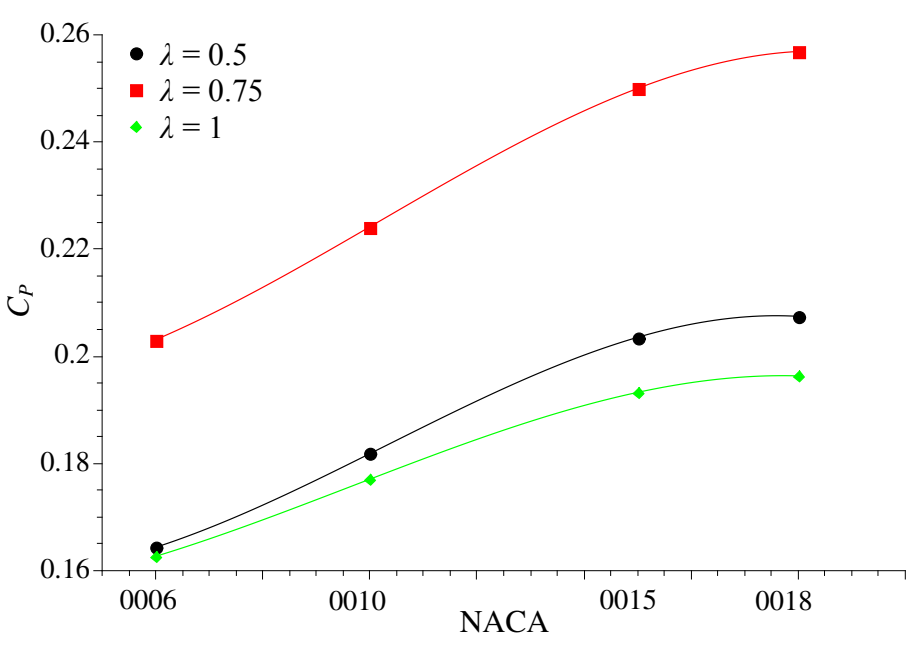

(b)

FIGURE 4. RESULTS OBTAINED FOR THE AIRFOIL THICKNESS. a) POWER COEFFICIENT VARIATION WITH TIP-SPEED RATIO. b) POWER COEFFICIENT VARIATION WITH AIRFOIL THICKNESS FOR DIFFERENT TIP-SPEED RATIOS.

$\left(\Psi=270^{\circ}\right)$. This effect is more pronounced in higher $c / R$, therefore the length of the chord should play a significant role in the aerodynamic efficiency of the rotor.

Figure 6 (a) shows the variation of $C_{P}$ with $\lambda$ for different chord lengths. For lower values of $C_{P}$ the rotor with larger blades $(c=0.375 \mathrm{~m})$ preforms better than the other two. This is mostly related to the fact that, at very low $\lambda$, the larger blades operate as more efficient drag devices. As the tip speed velocity is increased the rotor should start operating as a lift-based device. In the range of $0.6<\lambda<1$ the intermediate airfoil $(c=0.25 \mathrm{~m})$ preforms better. However above $\lambda=1$ the larger airfoils show a rapid decrease in $C_{P}$ in contradiction with the smallest airfoil ( $c=0.125 \mathrm{~m}$ ) where the maximum $C_{P}$ was computed between the values of $1<\lambda<1$.1. Figure 6 (b) shows the variation of $C_{P}$ with the chord length for different values of $\lambda$. One can observe that for low tip-speed-ratios, $\lambda=0.5$, the power coefficient increases with the chord length. However, there should exist a limit for the chord length where the $C_{P}$ is maximum. For $\lambda=1$ the optimum blade, for this specific rotor dimension and pitch amplitude, should have a chord length in the range of $0.2<c<0.25$.

\section{Location of the pitching axis}

The location of the pitching axis in terms of $x^{\prime} / c$ ratio is the last parameter to be analyzed. For this case a chord length of $c=0.25 \mathrm{~m}$ was selected together with a total of four NACA0018 blades.

Figure 7 (a) shows the variation of power coefficient with tip-speed-ratio. One can see that, for several values of $\lambda$, the $x^{\prime} / c=0.35$ is giving higher values of $C_{P}$. It is also observed that a more smooth distribution of $C_{P}$ is obtained when the pitching axis is located closer to half of chord length, $x^{\prime} / c=0.5$. In Fig. 7 (b) we have again plotted the $C_{P}$ variation with the geometrical parameter, for constant values of $\lambda$. Here is possible to observe that for the lowest and intermediate value of $\lambda$, the optimum location of the pitching axis should be in the range of $0.35<x^{\prime} / c<0.5$, and that this location is moved towards $x^{\prime} / c=0.5$ as we increase $\lambda$. 


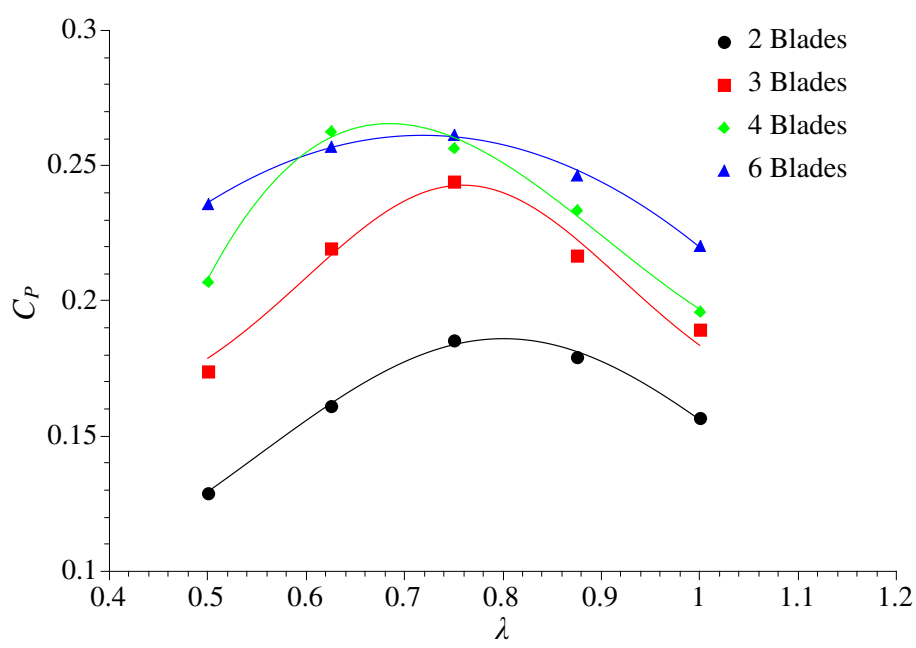

(a)

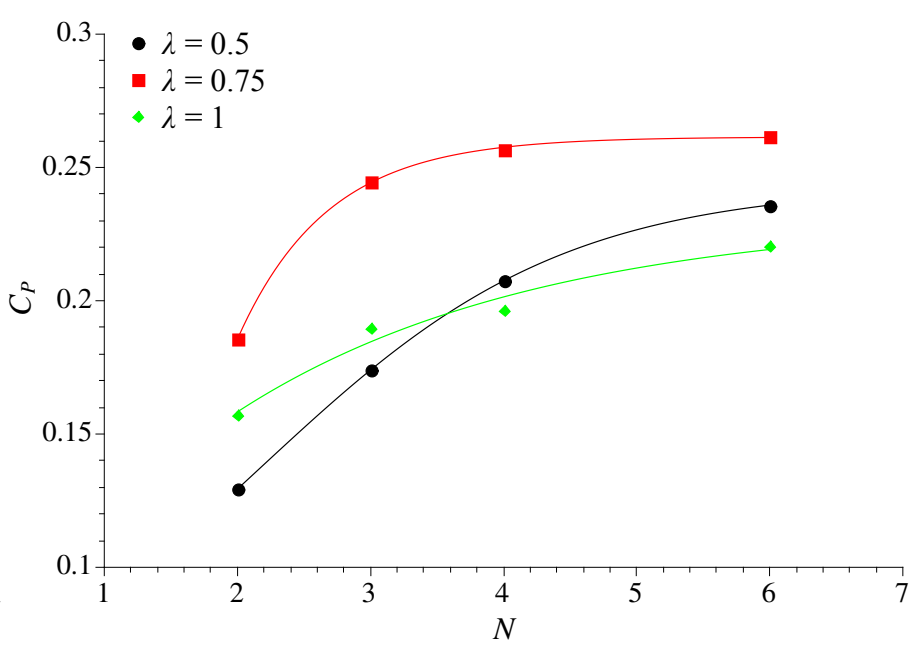

(b)

FIGURE 5. RESULTS OBTAINED FOR THE VARIATION OF THE NUMBER OF BLADES. a) POWER COEFFICIENT VARIATION WITH TIP-SPEED RATIO. b) POWER COEFFICIENT VARIATION WITH THE NUMBER OF BLADES FOR DIFFERENT TIP-SPEED RATIOS.

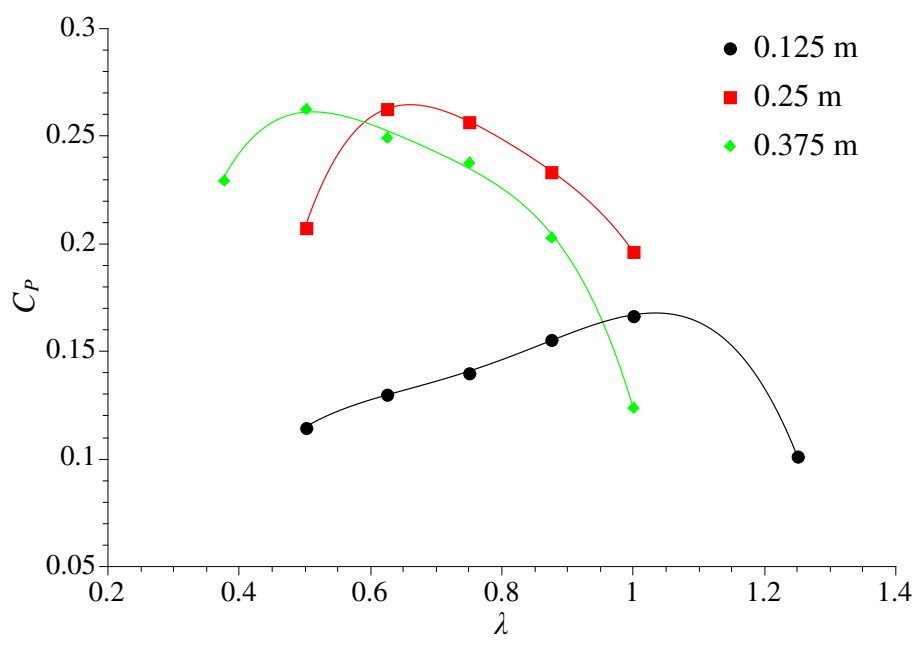

(a)

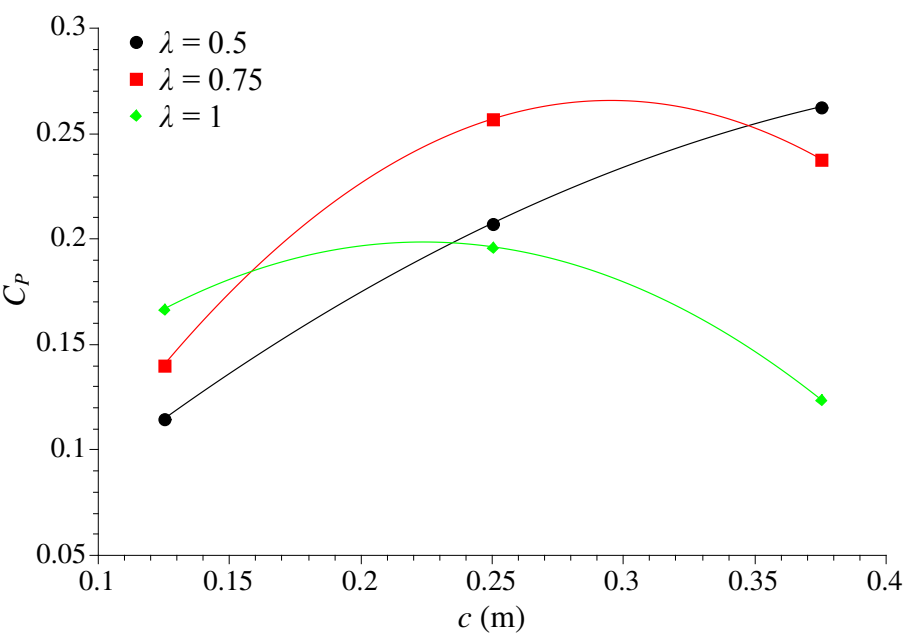

(b)

FIGURE 6. RESULTS OBTAINED FOR THE VARIATION OF BLADE CHORD LENGTH. a) POWER COEFFICIENT VARIATION WITH TIP-SPEED RATIO. b) POWER COEFFICIENT VARIATION WITH THE BLADE CHORD LENGTH FOR DIFFERENT TIP-SPEED RATIOS.

\section{COMPARISON WITH A FIXED PITCH VAWT}

In this section the proposed design is compared with a conventional fix pitch turbine. We assume that the optimized design is composed by a rotor with four NACA0018 blades with a pitching axis located at $35 \%$ of a chord length of $c=0.25 \mathrm{~m}$. We have selected this design since it was the one that reach the highest $C_{P}$ value in the last "trial and error" parametric analysis. However one can also verify that the six-bladed rotor is also very efficient for a wider range of $\lambda$.

Figure 8 (a) shows a comparison between the fixed and variable pitch turbines in a $C_{P}$ vs $\lambda$ plot. Three pitch amplitudes are analyzed in the variable (V) and fixed (F) pitch rotors, namely $\theta_{0}=5^{\circ} ; 15^{\circ} ; 30^{\circ}$. As expected, for the lowest $\lambda$, the $C_{P}$ increases with pitch amplitude, where the V-rotor with $\theta_{0}=30^{\circ}$ provides a $C_{P}$ four times superior to that provided by the F-rotor with $\theta_{0}=5^{\circ}$. One can also observe that the pitch amplitude must decrease as $\lambda$ increases. In particular one can verify that the V-rotor with $\theta_{0}=15^{\circ}$ is quite efficient in the range of $0.75<\lambda<1.5$ but if, for the same rotor, we decrease the amplitude into $\theta_{0}=5^{\circ}$, more efficiency is obtained for $\lambda$ values above 1.75. For an amplitude of $\theta_{0}=5^{\circ}$ the F-rotor gives a similar efficiency as the $\mathrm{V}$-rotor in the $0.75<\lambda<1.5$ range, but it cannot provide the 


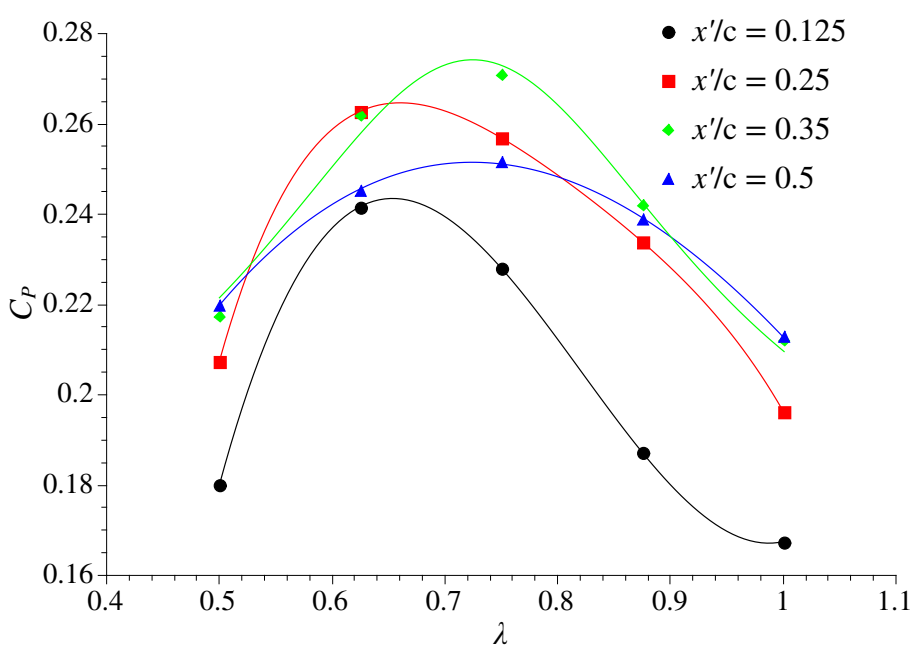

(a)

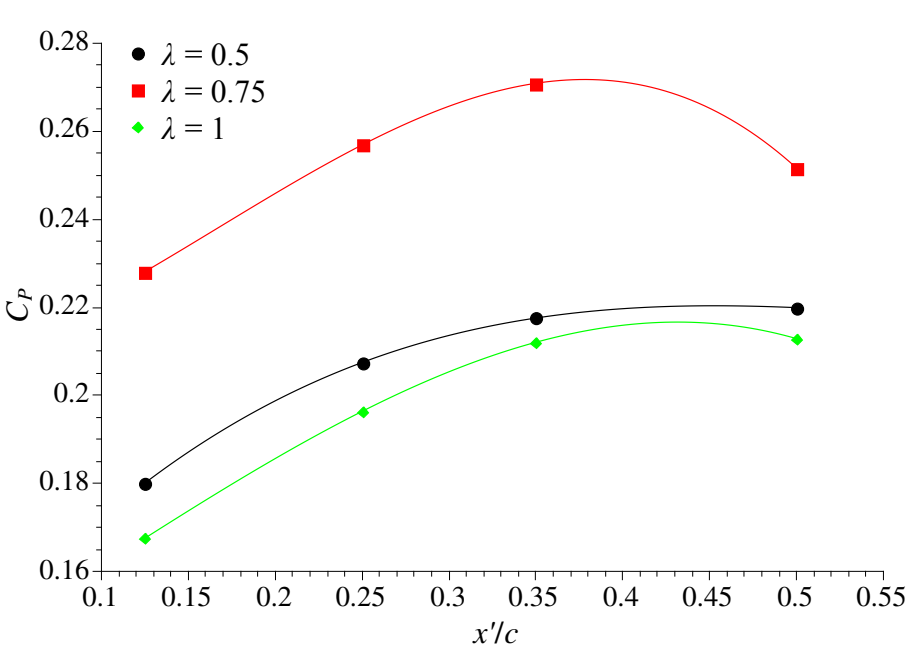

(b)

FIGURE 7. RESULTS OBTAINED FOR VARIATION OF THE PITCHING AXIS LOCATION. a) POWER COEFFICIENT VARIATION WITH TIP-SPEED RATIO. b) POWER COEFFICIENT VARIATION WITH THE PITCHING AXIS LOCATION FOR DIFFERENT TIP-SPEED RATIOS.

same torque in the remaining cases. The F-rotor with $\theta_{0}=15^{\circ}$ is here plotted to better illustrate the problems of VAWTs at low $\lambda$.

Figure 8 (a) shows the variation of $C_{P}$ with the azimuthal position of a single blade in a fixed $\left(\theta_{0}=5^{\circ}\right)$ and in a variable $\left(\theta_{0}=30^{\circ}\right)$ pitch rotor, for $\lambda=0.5$. One can easily verify that a significant higher value of power is extracted with the $\mathrm{V}$-rotor blade, when this is in the frontal region of the rotor $\left(0^{\circ}<\Psi<180^{\circ}\right)$, and that some power is also obtained in the backward region $\left(180^{\circ}<\Psi<360^{\circ}\right)$. With a F-rotor this is no longer possible: less power is extracted in the first two quadrants, and even some considerable negative torque is obtained in $90^{\circ}<\lambda<160^{\circ}$, meaning that the turbine blade is providing energy to the flow. These aspects are illustrated in Fig.9, where the contour plots of velocity magnitude ((a) and (b)) and nondimensional vorticity, with superimposed stream lines ((c) and (d)), are shown. In these plots on can observe that a more smooth flow is obtained with a variable pitch rotor, and that in the fixed pitch rotor a significant portion of kinetic energy is being converted into vorticity.

\section{CONCLUSIONS}

In this paper we have proposed design guidelines for what could be the next generation of vertical axis wind turbines. The proposed concept is based on a self-pitch turbine that prescribes a pitching schedule for the blades during the rotating cycle. We have demonstrated, trough the use of numerical tools, that the proposed concept, when compared with a classical fix pitch VAWT, can generate higher torque for lower tip-speed-ratios. Such increase for low and intermediate $\lambda$ is due to a reduction of the variation of the angle of attack, which reduces stall effects in several azimuthal positions of the rotor.

A parametric study was also preformed for several key geometrical parameters ruling the design of variable pitch turbines. One could verify that the aerodynamic efficiency, at high pitch amplitudes, increases with airfoil thickness until a maximum is obtained for the NACA0018 blade. Regarding the number of blades, our results show that higher torque can be obtain at low $\lambda$ values with the six-bladed rotor, and that more blades seem to give a slightly constant torque production over a wider range of $\lambda$. The results for the chord-to-radius ratio show that higher torque is produced a very low tip-speed-ratios with larger blades and that for the $c / R$ should decrease with $\lambda$. The CFD solution for the pitching axis location shows that, for a given $\theta_{0}$, the optimum location is also dependent on $\lambda$, but should be located in the range $0.35<x^{\prime} / c<0.5$.

For future work several topics must be addressed:

(1) Explore the effect of the Reynolds number.

(2) Analyse the rotor behaviour under realistic wind profiles.

(3) The definition of the optimum pitching schedule for the blades. This must be done in conjunction with the design of the mechanical system, since only structural viable pitching kinematics is allowed, for the sake of integrity.

(4) Full three-dimensional analysis of the rotor in different operational conditions.

\section{ACKNOWLEDGMENT}

The present work was supported by C-MAST, Centre for Mechanical and Aerospace Science and Technology Research Unit No. 151. 


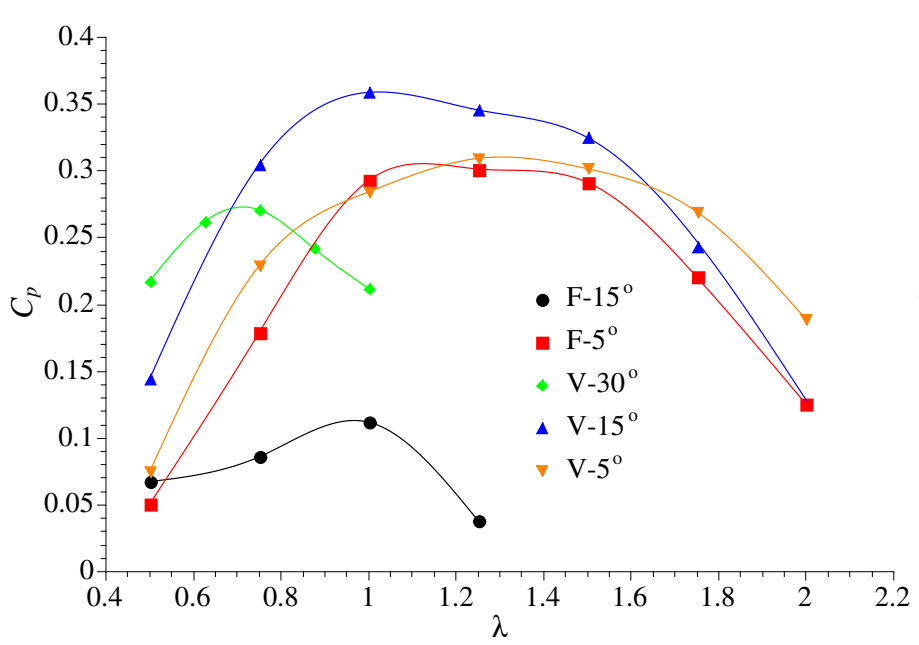

(a)

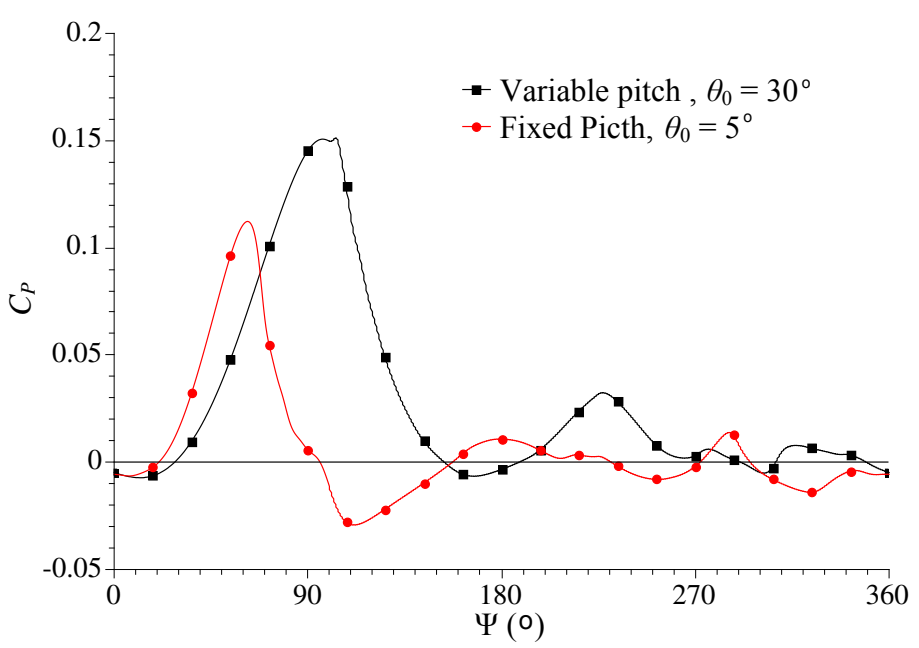

(b)

FIGURE 8. COMPARISON BETWEEN THE PROPOSED AND CONVENTIONAL DESIGN. a) POWER COEFFICIENT VARIATION WITH TIP-SPEED RATIO (F-FIXED PITCH, V-VARIABLE PITCH, FOR: $\theta_{0}=5^{\circ} ; 15^{\circ} ; 30^{\circ}$ ). b) POWER COEFFICIENT VARIATION WITH THE AZIMUTHAL POSITION OF ONE BLADE FOR $\lambda=0.5$.

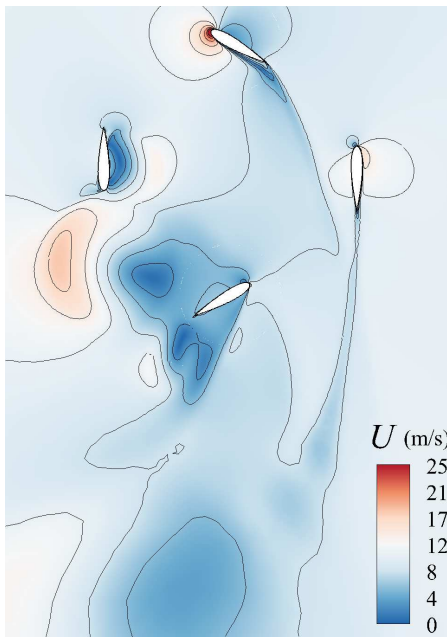

(a)

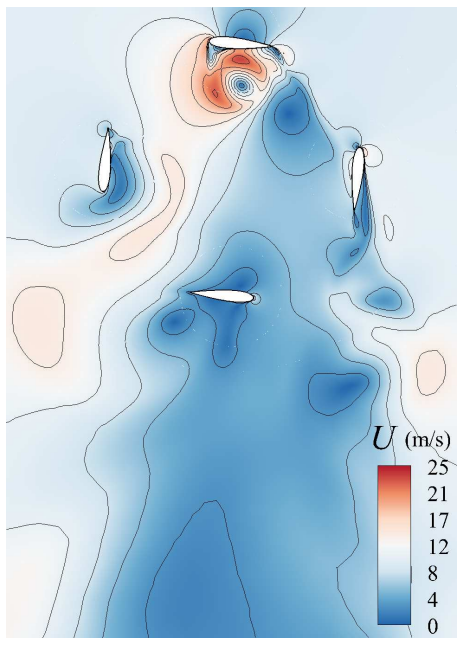

(b)

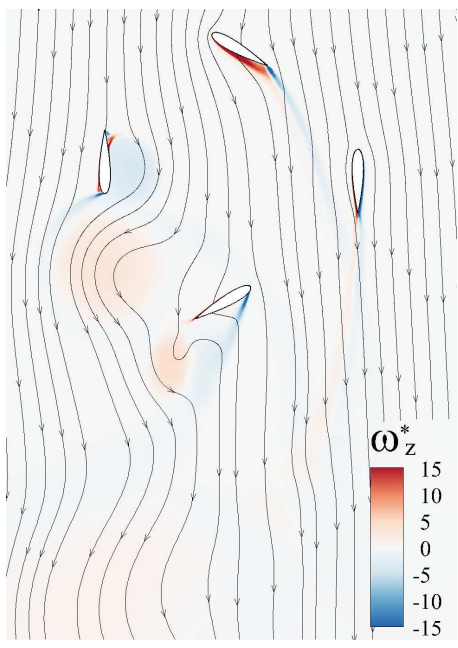

(c)

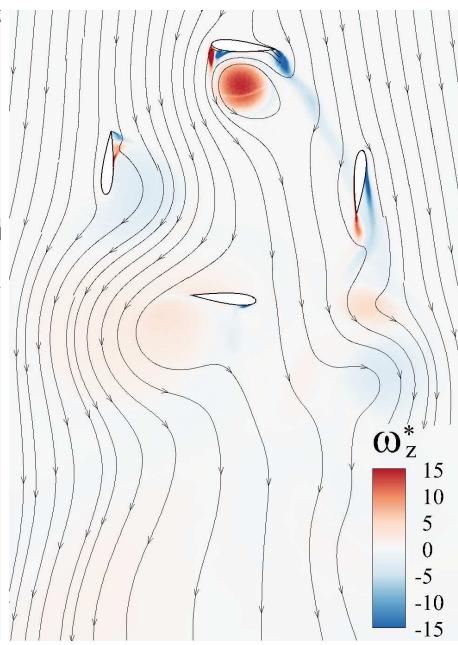

(d)

FIGURE 9. INSTANTANEOUS CONTOUR PLOTS OF VELOCITY MAGNITUDE $(\lambda=0.5)$ COMPUTED AFTER FIVE REVOLUTIONS IN THE: a) PROPOSED DESIGN $\left(c=0.25 \mathrm{~m} ; N=4\right.$; NACA0018; $\left.x^{\prime} / c=0.35 ; \theta_{0}=30^{\circ}\right)$; b) CONVENTIONAL ROTOR WITH A FIXED PITCH OF $5^{\circ}$. INSTANTANEOUS CONTOUR PLOTS FOR THE NON-DIMENSIONAL VORTICITY, $\omega_{z}^{*}=\omega_{z} c / U_{\text {wind }}$, WITH SUPER IMPOSED STREAMLINES: c) PROPOSED DESIGN; d)CONVENTIONAL ROTOR.

\section{REFERENCES}

[1] Xisto, C. M., Pascoa, J. C., Leger, J., and Trancossi, M., 2014. "Wind energy production using an optimized variable pitch vertical axis rotor". In ASME International Mechanical Engineering Congress \& Exposition, Vol. IMECE2014-38966.

[2] Benedict, M., Lakshminarayan, V., Pino, J., and Chopra, I., 2013. "Fundamental understanding of the physics of a small-scale vertical axis wind turbine with dynamic blade pitching: An experimental and computational approach". In 54th AIAA/ASME/ASCE/AHS/ASC Structures, Structural Dynamics, and Materials and Co-located Conferences, American Institute of Aeronautics and Astronautics.

[3] Madsen, H., and Lundgren, K., 1980. The Voith-Schneider Wind Turbine: Some Theoretical and Experimental Results on the Aerodynamics of the Voith-Schneider Wind Turbine. 
Institute of Industrial Constructions and Energy Technology Aalborg University Centre.

[4] Pawsey, N. C. K., 2002. "Development and evaluation of passive variable-pitch vertical axis wind turbines". $\mathrm{PhD}$ thesis, University of New South Wales.

[5] Duquette, M. M., and Visser, K. D., 2003. "Numerical implications of solidity and blade number on rotor performance of horizontal-axis wind turbines". Journal of Solar Energy Engineering, 125(4), pp. 425-432.

[6] Eriksson, S., Bernhoff, H., and Leijon, M., 2008. "Evaluation of different turbine concepts for wind power". Renewable and Sustainable Energy Reviews, 12(5), pp. 1419 1434.

[7] Mohamed, M., 2012. "Performance investigation of h-rotor darrieus turbine with new airfoil shapes". Energy, 47(1), pp. 522 - 530. Asia-Pacific Forum on Renewable Energy 2011.

[8] Roh, S.-C., and Kang, S.-H., 2013. "Effects of a blade profile, the reynolds number, and the solidity on the performance of a straight bladed vertical axis wind turbine". Journal of Mechanical Science and Technology, 27(11), pp. 3299-3307.

[9] Chougule, P., and Nielsen, S., 2014. "Overview and design of self-acting pitch control mechanism for vertical axis wind turbine using multi body simulation approach". Journal of Physics: Conference Series, 524(1), p. 012055.

[10] Hwang, S., Min, Y., Lee, H., and Kim, J., 2008. "Development of a Four-Rotor Cyclocopter". Journal of Aircraft, 45(6), Nov., pp. 2151-2157.

[11] Benedict, M., 2010. "Fundamental understanding of the cycloidal-rotor concept for micro air vehicle applications". Ph.d. diss., University of Maryland.

[12] Xisto, C. M., Páscoa, J. C., Leger, J. A., Masarati, P., Quaranta, G., Morandini, M., Gagnon, L., Schwaiger, M., and Wills, D., 2014. "Numerical modelling of geometrical effects in the performance of a cycloidal rotor". In 11th World Conference on Computational Mechanics, no. p1848.

[13] Benedict, M., Ramasamy, M., and Chopra, I., 2010. "Improving the Aerodynamic Performance of Micro-AirVehicle-Scale Cycloidal Rotor: An Experimental Approach". Journal of Aircraft, 47(4), July, pp. 1117-1125.

[14] Benedict, M., Jarugumilli, T., and Chopra, I., 2013. "Effect of Rotor Geometry and Blade Kinematics on Cycloidal Rotor Hover Performance". Journal of Aircraft, 50(5), Sept., pp. 1340-1352.

[15] Leger, J. A., Páscoa, J. C., and Xisto, C. M., 2015. “Analytical modeling of a cyclorotor in hovering state". Proceedings of the Institution of Mechanical Engineers, Part G: Journal of Aerospace Engineering, 0, p. 0.

[16] Xisto, C. M., Páscoa, J. C., Abdollahzadeh, M., Leger, J. A., Schwaiger, M., and Wills, D., 2014. "PECyT - Plasma Enhaced Cycloidal Thruster". In 50th
AIAA/ASME/SAE/ASEE Joint Propulsion Conference.

[17] Xisto, C. M., Pascoa, J. C., and Leger, J., 2014. "Сycloidal rotor propulsion system with plasma enhanced aerodynamics". In ASME International Mechanical Engineering Congress \& Exposition, no. IMECE2014-38291.

[18] Gagnon, L., Quaranta, G., Morandini, M., Masarati, P., Lanz, M., Xisto, C. M., and Pascoa, J. C., 2014. "Aerodynamic and aeroelastic analysis of a cycloidal rotor". In AIAA Modelling and Simulation Technologies Conference.

[19] Trancossi, M., Dumas, A., Xisto, C. M., Páscoa, J. C., and Andrisani, A., 2014. "Roto-cycloid propelled airship dimensioning and energetic equilibrium". In SAE 2014 Aerospace System and Technology Conference.

[20] Hansen, M. O., and Sørerensen, D. N., 2001. "CFD model for vertical axis wind turbine". In Proceedings of the 2001 European Wind Energy Conference and Exhibition, WIPRenewable Energies.

[21] Edwards, J. M., Angelo Danao, L., and Howell, R. J., 2012. "Novel experimental power curve determination and computational methods for the performance analysis of vertical axis wind turbines". Journal of Solar Energy Engineering, 134(3), May, pp. 031008-031008.

[22] ao Ferreira, C. J. S., Bijl, H., van Bussel, G., and van Kuik, G., 2007. "Simulating dynamic stall in a $2 \mathrm{~d}$ vawt: Modeling strategy, verification and validation with particle image velocimetry data". Journal of Physics: Conference Series, 75(1), p. 012023.

[23] Ferreira, C. J. S. a., van Zuijlen, A., Bijl, H., van Bussel, G., and van Kuik, G., 2010. "Simulating dynamic stall in a two-dimensional vertical-axis wind turbine: verification and validation with particle image velocimetry data". Wind Energy, 13(1), pp. 1-17.

[24] Ferreira, C. J. S. a., van Bussel, G. J. W., van Kuik, G. A. M., and Scarano, F., 2011. "On the use of velocity data for load estimation of a vawt in dynamic stall". Journal of Solar Energy Engineering, 133(1), Jan., pp. 011006011006.

[25] Spalart, P. R., and Rumsey, C. L., 2007. "Effective inflow conditions for turbulence models in aerodynamic calculations". AIAA Journal, 45(10), pp. 2544-2553. 